\title{
Development of the Learner Self-Directedness in the Workplace Scale
}

\author{
Authors: \\ Karina De Bruin ${ }^{1}$ \\ Gideon P. De Bruin² \\ Affiliations: \\ ${ }^{1}$ Department of Psychology, \\ University of Johannesburg, \\ South Africa \\ ${ }^{2}$ Department of Industrial \\ Psychology and People \\ Management, University of \\ Johannesburg, South Africa \\ Correspondence to: \\ Karina De Bruin \\ Email: \\ karinadb@uj.ac.za \\ Postal address: \\ PO Box 524, Auckland Park \\ 2006, South Africa

\section{Dates:} \\ Received: 26 July 2010 \\ Accepted: 19 May 2011 \\ Published: 10 Oct. 2011 \\ How to cite this article: \\ De Bruin, K., \& De Bruin, G.P. \\ (2011). Development of the \\ Learner Self-Directedness \\ in the Workplace Scale. \\ SA Journal of Industrial \\ Psychology/SA Tydskrif vir \\ Bedryfsielkunde, 37(1), Art. \\ \#926, 10 pages. doi:10.4102/ \\ sajip.v37i1.926

\section{Note:} \\ This article is based on \\ research that the National \\ Research Foundation, \\ under grant number \\ TTK2006051100008, \\ supports.
}

C 2011. The Authors. Licensee: AOSIS OpenJournals. This work is licensed under the Creative Commons Attribution License.
Orientation: This study reports on the development of an instrument that one can use to measure learner self-directedness in work environments.

Research purpose: The purpose of this study was to develop a scale to measure learner selfdirectedness in the workplace.

Motivation for the study: Learner self-directedness appears to be an essential characteristic to keep up with the demands of the world of work. There is no brief instrument currently available to measure learner self-directedness in the workplace.

Research design, approach and method: The researchers fitted the responses of 519 participants to 22 items to the Rasch rating scale model.

Main findings: The researchers retained 13 of the original 22 items. The hierarchy of item locations supported the construct validity of the scale. Hierarchical factor analysis showed the presence of one higher-order factor and three residual first-order factors. The higher-order factor accounted for almost five times as much of the common variance as did the strongest residual first-order factor. The Rasch analysis and the factor analysis suggested that the 13-item Learner Self-Directedness in the Workplace Scale (LSWS) measures a single one-dimensional construct $(\alpha=0.93)$.

Practical/managerial implications: The instrument can help employers to understand and support employees' self-directed learning efforts.

Contribution/value-add: This research resulted in a brief instrument to measure learner selfdirectedness in the workplace. This instrument is unique in the South African context.

\section{Introduction}

The concepts of self-directed learning and learner self-directedness have generated much research interest in the field of adult education and training in the last three decades.

Empirical research shows that self-directed learners are able to adapt to changes in their environments better, to realise their potential as leaders and to remain resilient in the face of career-related or educational challenges and obstacles (Guglielmino \& Murdick, 1997; Klute, Crouter, Sayer \& McHale, 2002; Zsiga, 2008). Most of the empirical research on self-directedness has focused on learning in higher education institutions (Pata, 2009). However, relatively little research has focused on the role of self-directed learning in career and human resource development in organisations, especially in countries other than the United States of America (Ellinger, 2004).

This may be a limitation because people develop and learn throughout adulthood in settings other than formal education institutions (Marsick, Watkins, Callahan \& Volpe, 2009). Furthermore, the rapidly changing world of work - internationally as well as in South Africa - and employees' continuous adjustment to these changes makes an investigation into the applicability of selfdirected learning in the workplace necessary (Baruch, 2006; Guglielmino, 2008; Sullivan \& Arthur, 2006).

The progress of research into self-directed learning in the workplace is partly because of the availability of a high quality instrument to measure learner self-directedness. The Self-Directed Learning Readiness Scale (SDLRS) is a well-researched instrument developed in the United States of America (see Guglielmino, 1977). It measures readiness for self-directed learning. It is widely used in research in higher education and organisational settings. 
However, researchers have challenged the psychometric integrity of the SDLRS (Cho, Ellinger \& Hezlett, 2006; De Bruin, Jacobs, Schoeman \& De Bruin, 2001; Field, 1990). In addition, it was originally developed for use in higher education rather than in organisational settings.

More recently, the Bartlett-Kotrlik Inventory of Self-Learning (BKISL) was developed for use in work environments (Bartlett \& Kotrlik, 1999). It consists of 11 factors and includes measures of personal, social and environmental variables that may affect self-learning. We know little about the psychometric properties of the BKISL; its reliability in different cultures also needs further investigation (Cho et al., 2006).

Against this background, the aim of this study was to develop a brief one-dimensional measure of learner self-directedness that focuses explicitly on learning in the workplace.

\section{Self-directed learning and learner self-directedness}

Malcolm Knowles (1975) considered applying the concept of self-directed learning, observed in informal learning projects during the early 1970s (Tough, 1971), to formal education.

In addition to acknowledging the relevance of this form of learning to the broader social, political and economic world of work, Knowles's (1975) unique contribution was his idea that self-directed learning is more appropriate to the individual's natural process of psychological development than are traditional educational methods.

According to him, becoming a self-directed learner mirrors the process of psychological maturation from complete dependence to self-sufficiency and personal responsibility for one's life. In becoming a self-directed learner, the person progressively acquires greater independence in the process of learning and increasingly accepts more responsibility for the process and its outcomes.

Knowles (1975) defined self-directed learning as:

... a process in which individuals take the initiative, with or without the help of others, in diagnosing their learning needs, formulating learning goals, identifying human and material resources for learning, choosing and implementing appropriate learning strategies, and evaluating learning outcomes.

(Knowles, 1975, p. 18)

Stated differently, self-directed learning is a process in which learners take primary responsibility for planning, implementing and assessing their learning efforts. A person who is ready for self-directed learning (Guglielmino, 1977) will have the willingness and the skills to engage in selfdirected learning activities. There are other definitions of self-directed learning (Blackwood, 1994; Hiemstra, 1994; Merriam \& Caffarella, 1991) but most of them echo Knowles's (1975) definition.

Brockett and Hiemstra (1991) built on this definition. They proposed the Personal Responsibility Orientation Model as a conceptual framework for self-directed learning. The model provided a framework for the interaction of internal and external factors that influence self-directed learning and reflected a synthesis of theoretical and empirical findings on this subject.

The concept of personal responsibility, which is when people take ownership and responsibility for their ideas and behaviours, is central to this model. In addition, the model posited that assuming personal responsibility is both 'desirable and effective' (Brockett \& Hiemstra, 1991, p. 101).

The model distinguishes between 'self-directed learning' and 'learner self-directedness'. 'Self-directed learning' is the process in which people accept the primary responsibility for planning, implementing and evaluating their learning. This implies a process perspective. On the other hand, 'learner self-directedness' refers to the person's need, or preference, for accepting responsibility for learning. This implies a disposition perspective.

Therefore, according to this model, self-directedness in learning refers to the teaching-learning process and the internal attributes, or disposition, of the learner.

There have been several studies to investigate the relationship between self-directedness and psychosocial or behavioural variables. They show that self-directed learners tend to display a unique personal orientation that comprises socio-demographic, psychological and personality aspects. Typically, their metacognitive capacities are strong and they are skilled in critical thinking, reflection, self-evaluation, creativity and problem solving (Patterson, Crooks \& LunykChild, 2002).

Self-directed learners prefer a converger learning style (Linares, 1999), which abstract conceptualisation and technical problem solving characterises. They are able to control themselves in the learning context and in learning tasks (Mok \& Lung, 2005).

These learners report positive self-esteem (Oliveria \& Simoes, 2006), a strong self-concept (Sabbaghian, 1980) and high levels of self-efficacy with regard to their self-directedness (Hoban \& Hoban, 2004). With regard to personality characteristics, the consensus amongst researchers, who use different techniques, is that there may be a prototypic self-directed learner. They have identified personality characteristics like curiosity, self-acceptance, conscientiousness, adaptability, flexibility, independence, warmth and cooperativeness (Chuprina \& Durr, 2006; De Bruin, 2007; Oliveira \& Simoes, 2006).

\section{Relevance of self-directed learning in the workplace}

Most of the research on self-directed learning and learner selfdirectedness has focused on higher education environments (Chakravarthi \& Vijayan, 2010; Pata, 2009; Raidal \& Volet, 2009). 
However, self-directed learning is not only relevant in institutions of formal education. It is also relevant in organisations and other work environments. The rapidly changing world of work generates a continuous flow of new information to which employers and employees may struggle to adjust (Baruch, 2006).

This new world of work may offer opportunities for greater self-fulfilment. However, career success will depend largely on the continuous updating of knowledge and skills (Briscoe \& Hall, 2006). It is important for employers to devise strategies and methodologies that could contribute to the ongoing knowledge and skills development of their employees (Arulmani \& Nag-Arulmani, 2004; Guglielmino, 2008).

Arulmani and Nag-Arulmani (2004) state that the future world of work may not keep offering jobs to people that they can follow in one lifetime. Instead, they are likely to change their jobs several times during their working life (Arthur, Khapova \& Wilderom, 2005). In addition, many jobs may change dramatically over relatively short periods. Therefore, employees will need to update their existing skills and knowledge constantly as well as acquire new skills and knowledge to meet the needs of organisations (Guglielmino \& Murdick, 1997).

According to Cseh, Watkins and Marsick (2000), the time lapse between knowledge acquisition and obsolescence is becoming shorter. Therefore, we need to explore ways of learning other than formal training. A high level of learner self-directedness may help employees to cope with the adjustment to these career-related demands. Bartlett and Kotrlik (1999) state that '... the rapid rate of change creates a long-term reason why self-directed learning is critical to function within society' (p. 185).

Organisations are likely to benefit from employees who are self-directed learners (Confessore \& Kops, 1998; Guglielmino, 2008). These employees have to keep up to date with developments in their respective fields of work, take responsibility for their own career and professional development and be open to changes in the work environment (Guglielmino \& Roberts, 1992). These employees are responsible, purposeful, resourceful, self-accepting and selfdisciplined. They rely on their own judgement (Klute et al., 2002).

According to Kops and Pilling-Cormick (2004), changes in training are obvious in organisations that promote selfdirected learning environments. These include modifications to approaches of evaluation, greater variation in training methods (e.g. online learning, mentorships, the formal exchange of expertise between coworkers and visits to other organisations) and changes in the responsibilities and skills of trainers.

The benefits of self-directed learning are not limited to organisations. Employees can also gain much from working in organisations that promote self-directed learning and learner self-directedness. These organisations will be more responsive to the specific needs of individual employees, will allow greater flexibility in work schedules and will encourage workers to update their skills and knowledge (Merriam, 1993; Puskirich, 1993). In turn, self-directed employees may develop metaskills for approaching and solving problems outside of their immediate assignments and become more self-confident as well as more independent in solving workrelated problems (Guglielmino \& Murdick, 1997).

Despite the relevance of learner self-directedness in the workplace, there is an absence of research in organisations outside of the United States of America. In addition, instruments to measure it effectively are necessary. Making quality and brief measures of learner self-directedness in the workplace available may address Ellinger's (2004) suggestion for further research and support interventions aimed at improving self-directedness in adult workers.

Against this background, the present study aimed to develop a brief measure of learner self-directedness in the workplace.

\section{Research design Research approach}

This is a nonexperimental psychometric study. Its aim was to develop a new measure of learner self-directedness in the workplace.

\section{Research method}

\section{Research procedure}

The researchers followed the steps for constructing scales that Netemeyer, Bearden and Sharma (2003) described.

Firstly, the researchers defined the concept of self-directed learning using their findings from the literature. Although there are various definitions, almost all of them include Knowles's (1975) focus on the responsibility of people for their own learning attempts. Therefore, the researchers decided to emphasise the idea of individual responsibility when defining the concept. As Brockett and Hiemstra (1991) also suggested, internal ('learner self-directedness') and external ('self-directed learning') factors may influence individual responsibility for learning.

In this study, the researchers acknowledged the crucial role of external factors in learning. However, they focused on 'learner self-directedness' - the internal dispositional perspective. Therefore, they used the following definition to help them develop the scale: 'learner self-directedness is an internal disposition that motivates learners to take responsibility for their own learning'. Furthermore, they decided to treat the concept as one-dimensional and constructed each item to reflect the latent concept of learner self-directedness.

In the second step, the researchers generated 22 items for the new scale of learner self-directedness in the workplace 
(Netemeyer et al., 2003). Each item reflected activities that that would indicate self-directed learning behaviour.

To avoid ambiguity, the researchers worded all items positively. Respondents indicated their agreement or disagreement with the items on a 5-point Likert-type scale. An initial review of the instrument involved an expert in the field of test construction and personality psychology. The researchers revised the items using the comments they received from this expert.

\section{Research participants}

The participants represented workers from various organisational settings. They included higher education institutions, schools, banks, publishing companies, law firms and broadcasting companies. The management structures in these organisations approved the participation of their employees in the research.

Of the 519 participants who completed the 22 items and a biographical questionnaire, 66 were men, 443 were women and ten participants did not indicate their gender. The mean age of the participants was $33.22(\mathrm{SD}=10.24)$. The sample included participants from the following groups: 79 were Black people, 394 were White people, 19 were Coloured people and 26 were Asians. One person did not indicate his or her group. The first author distributed most of the questionnaires to the participants. As part of their course requirements, students in a Career Psychology module also distributed questionnaires to working adults.

\section{Ethics}

The participants received covering letters that assured them of the confidentiality and anonymity of their responses. Participation in the study was free and voluntary and participants could decline to participate if they chose to. The researchers treated all data confidentially and did not ask for any personally identifying information. Participants had access to the final research report.

\section{Statistical analysis}

The researchers fitted the participants' responses to the questionnaire items to the Rasch rating scale model (Andrich, 1978; Wright \& Masters, 1982), which is suitable for analysing scales with Likert-type items. Rasch analyses provide three sets of important results. These are item parameters, person parameters and item and person fit statistics.

Item parameters reflect the relative difficulty of agreeing with items. They indicate the location of particular items on the latent trait continuum. Researchers often refer to them as item location parameters. Items with higher locations are more difficult to agree with than are items with lower location parameters. Person parameters reflect the relative standing of people on the latent trait continuum that underlies the scale. It indicates the location of people on the latent trait continuum. People with higher locations possess more of the trait than do people with lower locations. Both sets of parameters are expressed on the same linear logit scale. It allows for a direct comparison of people and items.

Once one knows the person and item parameters, it is possible to calculate an expected score for any particular person on any particular item. Rasch (1960) models are measurement ideals. One expects people with higher locations on the interest trait to obtain higher scores on all the items than do persons with lower standings on the trait. Similarly, one expects people to obtain lower scores on items that are more difficult to endorse than on items that are easier to endorse (Bond \& Fox, 2007). Rasch models require that the set of items defines a one-dimensional scale and that the items should be locally independent conditional on the latent trait (Wright \& Masters, 1982).

One expresses the degree to which items fit the requirements of the Rasch model as an outfit mean square statistic, which has an expected value of 1.00 , if the data fits the requirements of the model. Outfit mean squares $>1.00$ indicate underfit, whereas outfit mean squares $<1.00$ indicate overfit.

Overfit generally suggests redundancy in item content and is less concerning than underfit, which indicates that variables other than the trait of interest influence responses to the item. One calculates an outfit mean square for each item and an average outfit mean square as an indication of overall fit. Outfit mean squares between 0.75 and 1.33 indicate satisfactory fit (Wilson, 2005). However, one also considers the fit of items relative to one another when examining fit.

Rasch models dictate that person and item parameters should be independent of each other. Therefore, the item parameters should be invariant across different groups of people and the person parameters should be invariant across different sets of items. These requirements provide another way of inspecting the fit of data to the model. Specifically, one finds support for the measurement integrity of a scale if the item parameters remain invariant across groups of people with different trait levels and different biographical backgrounds (Andrich, 1978). One tests the null hypothesis of invariant item parameters across groups using a Pearson Chi-square statistic. To prevent Type 1 errors, one applies a Bonferonni correction by setting the alpha level at 0.05 divided by the number of item parameters one is comparing.

The researchers also fitted the data to a hierarchical factor analysis model to validate the structure of the questionnaire (Gorsuch, 1983; McDonald, 1999). To obtain the hierarchical solution, one obtains first-order (or primary) factors and then subjects them to a second-order analysis. One then transforms the solution to an orthogonal hierarchical structure using the Schmid and Leiman (1957) transformation (see Wolff \& Preissing, 2005). A strong higher order factor, accompanied by relatively weak residualised primary factors, supports one-dimensionality. 


\section{Results}

\section{Rasch rating scale model}

The researchers fitted responses to the 22 items to the Rasch rating scale model (Andrich, 1978; Wright \& Masters, 1982) using Winsteps version 3.68 (Linacre, 2009) to identify items that produce inconsistent responses conditional on the trait.

\section{Calibration and replication groups}

The researchers split the sample into a calibration group ( $n=261)$ and a replication group $(n=258)$ to examine the reproducibility of the item fit statistics. The outfit mean square fit statistics for the calibration and replication groups had a high correlation $(r=0.97)$. Inspection of the fit statistics in the two groups showed that the researchers could make identical decisions about whether to include individual items in the two groups or to exclude them. The researchers then pooled the data of the two groups to obtain more stable item fit statistics and item location parameters.

\section{Item fit and item selection in the pooled sample}

The Rasch rating scale analysis of the 22-item scale produced a person separation reliability of 0.87 . The corresponding Cronbach alpha coefficient was 0.93 . These coefficients are satisfactory. The average outfit mean square was 1.07, suggesting that the data as a whole under-fitted the model. The standard deviation of the outfit mean square was 0.63 . This indicates a large degree of variation in the fit of the individual items.
Table 1 shows that items 1, 2, 6, 9, 12, 20 and 21 had large outfit mean squares relative to the other items in the scale. These items also had relatively low item-measure correlations relative to the other items in the scale and to their expected correlations. A new analysis, without the misfitting items, also revealed that items 11 and 18 did not fit.

The researchers repeated the Rasch rating scale analysis without items 1, 2, 6, 9, 11, 12, 18, 20 and 21. This produced a 13 -item scale with a person separation reliability of 0.86 and a Cronbach coefficient alpha of 0.93 . Therefore, the reliability of the reduced scale was almost equal that of the 22-item scale. The average outfit mean square of the reduced scale was 0.99 and had a standard deviation of 0.16 . All the items had satisfactory outfit mean squares (see Table 2). They ranged between 0.76 (item 10) and 1.26 (item 3). The item-measure correlations ranged between 0.53 (item 16) and 0.79 (item 10). This shows that all 13 items had a strong relationship with the underlying trait. These correlations were close to the expected ones.

In general, these results suggest that the 13 remaining items define a one-dimensional scale that succeeds in separating persons with different trait levels. The items appear to elicit responses that agree with the model expectations and function as a coherent unit.

On the other hand, the nine items that the researchers deleted elicited unexpected responses and appeared to measure other dimensions as well as the principal dimension of interest.

TABLE 1: Rasch item calibrations and fit statistics for 22 items (sorted according to fit).

\begin{tabular}{|c|c|c|c|c|c|c|}
\hline \multirow[t]{2}{*}{ Item } & \multirow[t]{2}{*}{ Location } & \multirow[t]{2}{*}{ SE } & \multicolumn{2}{|c|}{ Outfit } & \multicolumn{2}{|c|}{ Point-measure correlation } \\
\hline & & & MNSQ & $t$ & Observed & Expected \\
\hline 1 & -0.22 & 0.06 & 3.11 & 9.9 & 0.31 & 0.53 \\
\hline 20 & 0.07 & 0.06 & 2.63 & 9.9 & 0.32 & 0.57 \\
\hline 6 & -0.31 & 0.07 & 1.67 & 6.4 & 0.38 & 0.53 \\
\hline 2 & -0.64 & 0.07 & 1.23 & 2.2 & 0.49 & 0.49 \\
\hline 9 & 1.32 & 0.05 & 1.25 & 3.7 & 0.59 & 0.68 \\
\hline 21 & 0.35 & 0.06 & 1.03 & 0.4 & 0.56 & 0.59 \\
\hline 11 & 0.18 & 0.06 & 0.95 & -0.7 & 0.59 & 0.58 \\
\hline 18 & -0.03 & 0.06 & 0.95 & -0.6 & 0.55 & 0.55 \\
\hline 16 & -0.90 & 0.08 & 0.82 & -1.8 & 0.50 & 0.46 \\
\hline 14 & 0.30 & 0.06 & 0.80 & -2.9 & 0.65 & 0.59 \\
\hline 22 & 0.13 & 0.06 & 0.76 & -3.4 & 0.61 & 0.57 \\
\hline 7 & 0.63 & 0.05 & 0.82 & -2.7 & 0.68 & 0.62 \\
\hline 13 & -0.49 & 0.07 & 0.66 & -4.1 & 0.62 & 0.50 \\
\hline 19 & 0.24 & 0.06 & 0.81 & -2.7 & 0.64 & 0.58 \\
\hline 5 & -0.14 & 0.06 & 0.80 & -2.6 & 0.59 & 0.54 \\
\hline 8 & 0.57 & 0.05 & 0.80 & -3.1 & 0.67 & 0.61 \\
\hline 4 & -0.33 & 0.07 & 0.66 & -4.4 & 0.63 & 0.52 \\
\hline 15 & -0.50 & 0.07 & 0.66 & -4.2 & 0.62 & 0.50 \\
\hline 17 & -1.02 & 0.08 & 0.61 & -3.9 & 0.56 & 0.44 \\
\hline 10 & 0.82 & 0.05 & 0.56 & -7.9 & 0.74 & 0.64 \\
\hline MEAN & 0.00 & 0.06 & 1.07 & -0.6 & - & - \\
\hline SD & 0.54 & 0.01 & 0.63 & 4.5 & - & - \\
\hline
\end{tabular}

$\mathrm{SE}$, standard error; MNSQ, mean square statistics; SD, standard deviation. 


\section{Invariance of item parameters}

Another way of examining fit is to evaluate the invariance of item parameters across different groups. According to the Rasch model, item parameters should be independent of the particular sample of people on which they were calibrated.

Against this background, the researchers used Pearson Chisquared statistics to compare the item location parameters of:

- men $(n=66)$ and women $(n=443)$

- the calibration $(n=261)$ and replication groups $(n=258)$

- participants with high levels of the trait $(n=333)$ and those with low levels of the trait $(n=134)$.

To guard against Type 1 errors, the researchers applied the Bonferonni correction to each of the three analyses. This yielded an alpha level of $0.05 \div 13=0.004$.

Table 3 shows that, for the gender and the calibrationreplication comparison, the researchers had to retain the null hypothesis of invariant item parameters for all 13 items. For the high-low comparison, the researchers had to reject the null hypothesis of an invariant item parameter for item 13.

\section{Comparison of person and item locations}

Figure 1 shows the locations of persons relative to the item locations on a so-called Wright item-person map (Wilson, 2005). This map capitalises on the joint scaling of persons and items on the same logit scale. Persons who occupy a higher location on the vertical latent trait continuum have higher levels of the trait of workplace learner self-directedness. Similarly, items that occupy a higher location reflect higher levels of the trait.

Figure 1 and Table 2 show a relatively good spread of item locations. They range between -1.33 logits (item 17: 'I enjoy learning new things that contribute toward my work performance') and 1.25 logits (item 10: 'I frequently investigate opportunities to learn more about my work'). The participants were also well spread along the latent trait continuum. This shows the high reliability of the scale.

In general, the participants reported high levels of selfdirectedness and found the majority of the items relatively easy to agree with.

TABLE 2: Rasch item calibrations and fit statistics for 13 items (sorted according to fit).

\begin{tabular}{|c|c|c|c|c|c|c|}
\hline \multirow[t]{2}{*}{ Item } & \multirow[t]{2}{*}{ Location } & \multirow[t]{2}{*}{ SE } & \multicolumn{2}{|c|}{ Outfit } & \multicolumn{2}{|c|}{ Point-measure correlation } \\
\hline & & & MNSQ & $t$ & Observed & Expected \\
\hline 3 & 0.02 & 0.07 & 1.26 & 3.0 & 0.65 & 0.67 \\
\hline 19 & 0.41 & 0.07 & 1.25 & 3.1 & 0.67 & 0.70 \\
\hline 16 & -1.18 & 0.09 & 1.17 & 1.4 & 0.53 & 0.57 \\
\hline 22 & 0.25 & 0.07 & 1.06 & 0.8 & 0.65 & 0.69 \\
\hline 5 & -0.13 & 0.07 & 1.10 & 1.2 & 0.64 & 0.66 \\
\hline 14 & 0.49 & 0.07 & 0.97 & -0.4 & 0.71 & 0.71 \\
\hline 13 & -0.62 & 0.08 & 0.88 & -1.3 & 0.65 & 0.62 \\
\hline 7 & 0.98 & 0.06 & 1.00 & 0.0 & 0.75 & 0.73 \\
\hline 8 & 0.88 & 0.07 & 0.96 & -0.5 & 0.74 & 0.73 \\
\hline 4 & -0.40 & 0.08 & 0.87 & -1.5 & 0.67 & 0.64 \\
\hline 17 & -1.33 & 0.09 & 0.78 & -1.8 & 0.59 & 0.56 \\
\hline 15 & -0.63 & 0.08 & 0.82 & -2.0 & 0.66 & 0.62 \\
\hline 10 & 1.25 & 0.06 & 0.76 & -3.9 & 0.79 & 0.75 \\
\hline SD & 0.78 & 0.01 & 0.16 & 2.0 & - & - \\
\hline
\end{tabular}

$\mathrm{SE}$, standard error; MNSQ, mean square statistics; SD, standard deviation.

TABLE 3: Comparison of item locations across different groups.

\begin{tabular}{|c|c|c|c|c|c|c|c|c|c|c|c|c|}
\hline \multirow[t]{2}{*}{ Item } & \multicolumn{2}{|c|}{ Item locations } & \multirow[t]{2}{*}{ Chi-square } & \multirow[t]{2}{*}{$p$} & \multicolumn{2}{|c|}{ Item locations } & \multirow[t]{2}{*}{ Chi-square } & \multirow[t]{2}{*}{$p$} & \multicolumn{2}{|c|}{ Item locations } & \multirow[t]{2}{*}{ Chi-square } & \multirow[t]{2}{*}{$p$} \\
\hline & Men & Women & & & Calibration & Replication & & & Low trait level & High trait level & & \\
\hline 3 & 0.30 & 0.02 & 1.85 & 0.174 & 0.05 & -0.03 & 0.30 & 0.5845 & 0.05 & -0.03 & 1.92 & 0.1656 \\
\hline 4 & -0.46 & -0.40 & 0.10 & 0.759 & -0.43 & -0.38 & 0.11 & 0.7413 & -0.43 & -0.38 & 7.48 & 0.0062 \\
\hline 5 & 0.14 & -0.18 & 2.06 & 0.151 & 0.00 & -0.26 & 0.90 & 0.884 & 0.00 & -0.26 & 5.97 & 0.0146 \\
\hline 7 & 0.89 & 0.98 & 0.16 & 0.689 & 0.98 & 0.98 & 0.00 & 1.0000 & 0.98 & 0.98 & 0.00 & 1.0000 \\
\hline 8 & 0.53 & 0.92 & 3.48 & 0.062 & 0.78 & 0.97 & 2.11 & 0.1462 & 0.78 & 0.97 & 1.27 & 0.2590 \\
\hline 10 & 0.82 & 1.29 & 5.57 & 0.018 & 1.22 & 1.28 & 0.19 & 0.6592 & 1.22 & 1.28 & 5.14 & 0.0233 \\
\hline 13 & -0.22 & -0.74 & 4.81 & 0.028 & -0.70 & -0.55 & 0.78 & 0.3782 & -0.70 & -0.55 & 13.68 & 0.0002 \\
\hline 14 & 0.13 & 0.49 & 2.65 & 0.104 & 0.43 & 0.54 & 0.62 & 0.4307 & 0.43 & 0.54 & 1.55 & 0.2134 \\
\hline 15 & -0.75 & -0.59 & 0.39 & 0.533 & -0.78 & -0.51 & 2.61 & 0.1061 & -0.78 & -0.51 & 4.18 & 0.0408 \\
\hline 16 & -0.93 & -1.18 & 0.76 & 0.384 & -1.09 & -1.26 & 0.87 & 0.3502 & -1.09 & -1.26 & 0.15 & 0.6966 \\
\hline 17 & -0.99 & -1.36 & 1.88 & 0.171 & -1.30 & -1.37 & 0.13 & 0.7199 & -1.30 & -1.37 & 1.95 & 0.1624 \\
\hline 19 & 0.65 & 0.41 & 1.42 & 0.234 & 0.48 & 0.35 & 0.79 & 0.3740 & 0.48 & 0.35 & 1.65 & 0.1994 \\
\hline 22 & 0.30 & 0.25 & 0.02 & 0.881 & 0.36 & 0.15 & 2.04 & 0.1528 & 0.36 & 0.15 & 8.64 & 0.0033 \\
\hline
\end{tabular}

$p$, probability value. 
Most of the items target the lower end of the person distribution. This shows that the scale is able to discriminate between people with relatively low levels of self-directedness better.

The large difference between the mean person location ( $\mathrm{B}=2.14$ logits, $\mathrm{SD}=1.56$ logits $)$ and the mean item location $(\mathrm{D}=0.00$ logits, $\mathrm{SD}=0.78$ logits $)$ reflects the relative mismatch between the person and item locations.

\section{Hierarchical factor analysis}

The researchers also subjected the responses to the 13 remaining items to a principal axis factor analysis. The screeplot and the Eigenvalues $>1$ criterion suggested three factors. The root mean square residual for the 3-factor solution was 0.03 . This shows that the solution gave a very good account of the covariances of the items.

Table 4 gives the oblique Direct Quartimin rotated 3-factor pattern matrix. Items 7, 8, 10 and 14 loaded onto factor 1 and seem to show an 'active learning' dimension. Figure 1 shows that these items were the most difficult to agree with in the Rasch analysis. Items 13, 15, 16, 17 and 19 loaded onto factor 2 and seem to show a 'learning is fun' dimension. Figure 1 shows that these items were the easiest to agree with. Items 3, 4, 5 and 22 loaded onto factor 3 and seem to show a 'motivated to learn' dimension.

The relatively strong correlations between the three factors suggested the presence of a higher order factor. Factors 1 and 2 had a correlation of 0.58 , factors 2 and 3 had one of 0.64 whilst factors 1 and 3 had a correlation of 0.66 .

A second-order factor analysis with a Schmid-Leiman transformation produced a hierarchical orthogonal solution with one higher-order factor and three residualised firstorder factors (see Table 5). The higher-order factor accounted for approximately $68 \%$ of the common variance of the items, whereas the residualised first-order factors accounted for approximately $13 \%, 9 \%$ and $11 \%$ respectively. Therefore, the higher-order factor accounted for almost five times as much of the common variance as did the strongest residualised first-order factor. Against this background, and the results of the Rasch analysis, it appears that the 13 items measure a one-dimensional construct, which we could call learner selfdirectedness in the workplace.

\section{Discussion}

The aim of this study was to develop an instrument to measure learner self-directedness in the workplace. The researchers applied the Rasch rating scale model and hierarchical factor analysis to construct a one-dimensional and reliable brief measure of self-directedness, the LSWS. The paragraphs that follow discuss the results against the background of the aims of the study, previous research and theory.

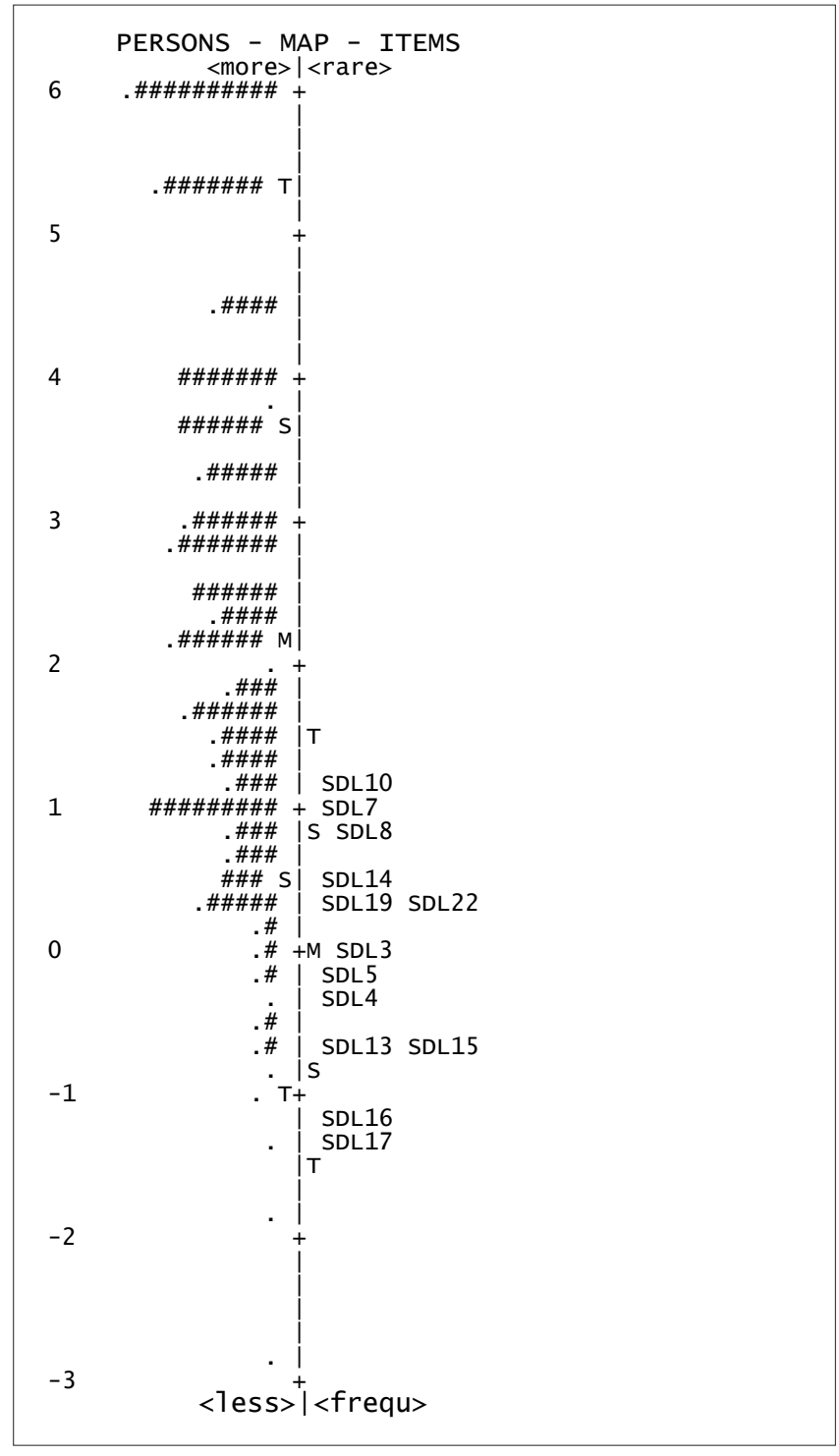

Note: Each \# represents four participants.

FIGURE 1: Wright item-person map of the Learner Self-Directedness in the Workplace Scale.

\section{The dimensions of the Learner Self-Directedness in the Workplace Scale}

The results of the Rasch analysis and the hierarchical factor analysis showed that the 13 items the researchers retained constitute a coherent and essentially one-dimensional scale. The hierarchical factor analysis revealed the presence of three minor residualised primary factors. However, these factors were weak compared to the general factor the items measured. The primary factors are unlikely to distort conclusions about a person's overall level of self-directedness based on the total score.

In addition, the Rasch analysis revealed that, on average, the locations of the items that define the three primary factors differed. The items most difficult to agree with define the first primary factor ('active learning'). The items that are easiest to agree with define the second primary factor ('learning is fun') whilst the items of medium difficulty define the third factor ('motivated to learn'). This suggests that the observed factors 
Item

3. I go out of my way to improve my work related skills.

4. I motivate myself to learn something new about my work.

5. I make a special effort to keep up with developments in my job.

7. I am constantly on the lookout for courses or books about my work.

8. I often read to improve my work-related knowledge and skills.

10. I frequently investigate opportunities to learn more about my work.

13. It is exciting to learn new things that widen my work-related skills.

14. I enjoy reading about different aspects of my work.

15. I am keen to develop my work-related knowledge and skills.

16. I get excited when I learn new skills.

17. I enjoy learning new things that contribute toward my work performance.

19. I often choose to learn new things about work even if it does not form part of formal learning situations.

22. I constantly try to keep up with developments in my field of work.

\begin{tabular}{lccc} 
& \multicolumn{3}{l}{ Factor } \\
\cline { 2 - 4 } & $\mathbf{1}$ & $\mathbf{2}$ & $\mathbf{3}$ \\
\hline & 0.00 & 0.21 & $\underline{0.58}$ \\
& 0.09 & 0.10 & $\underline{0.68}$ \\
& -0.05 & -0.09 & $\underline{0.90}$ \\
& $\underline{0.76}$ & 0.04 & 0.05 \\
& $\underline{0.84}$ & -0.06 & 0.05 \\
& $\underline{0.57}$ & -0.01 & 0.31 \\
& $\underline{0.37}$ & $\underline{0.50}$ & 0.02 \\
& $\underline{0.80}$ & 0.07 & -0.03 \\
& 0.34 & $\underline{0.52}$ & 0.02 \\
& -0.01 & $\underline{0.70}$ & 0.01 \\
\hline & -0.12 & $\underline{0.86}$ & 0.11 \\
& 0.26 & $\underline{0.43}$ & 0.10 \\
& 0.12 & 0.05 & $\underline{0.55}$
\end{tabular}

Note: Factor pattern coefficients $>0.30$ are underlined.

TABLE 5: Schmid-Leiman hierarchical factor solution for the learner self-directedness items.

\begin{tabular}{|c|c|c|c|c|}
\hline \multirow[t]{2}{*}{ Item } & \multicolumn{3}{|c|}{ Factor } & \multirow[b]{2}{*}{ General factor } \\
\hline & 1 & 2 & 3 & \\
\hline 3. I go out of my way to improve my work related skills. & -0.02 & $\underline{0.33}$ & 0.20 & $\underline{0.63}$ \\
\hline 4. I motivate myself to learn something new about my work. & 0.05 & $\underline{0.38}$ & 0.13 & $\underline{0.69}$ \\
\hline 5. I make a special effort to keep up with developments in my job. & 0.02 & $\underline{0.53}$ & -0.05 & $\underline{0.63}$ \\
\hline 7. I am constantly on the lookout for courses or books about my work. & $\underline{0.48}$ & 0.02 & 0.04 & $\underline{0.66}$ \\
\hline 8. I often read to improve my work-related knowledge and skills. & $\underline{0.54}$ & 0.02 & -0.03 & $\underline{0.66}$ \\
\hline 10. I frequently investigate opportunities to learn more about my work. & $\underline{0.37}$ & 0.17 & 0.02 & $\underline{0.70}$ \\
\hline 13. It is exciting to learn new things that widen my work-related skills. & 0.20 & -0.02 & $\underline{0.37}$ & $\underline{0.68}$ \\
\hline 14. I enjoy reading about different aspects of my work. & $\underline{0.50}$ & -0.01 & 0.04 & $\underline{0.65}$ \\
\hline 15. I am keen to develop my work-related knowledge and skills. & 0.18 & 0.01 & $\underline{0.36}$ & $\underline{0.68}$ \\
\hline 16. I get excited when I learn new skills. & -0.03 & -0.01 & $\underline{0.46}$ & $\underline{0.51}$ \\
\hline 17. I enjoy learning new things that contribute toward my work performance. & -0.06 & 0.10 & $\underline{0.47}$ & $\underline{0.62}$ \\
\hline 19. I often choose to learn new things about work even if it does not form part of formal learning situations. & 0.12 & 0.04 & $\underline{0.34}$ & $\underline{0.61}$ \\
\hline 22. I constantly try to keep up with developments in my field of work. & 0.11 & $\underline{0.33}$ & 0.02 & $\underline{0.57}$ \\
\hline
\end{tabular}

Note: Factor pattern coefficients $>0.30$ are underlined.

may be artefacts because of differential difficulty (McDonald, 1999).

The reliability of the total score was high. This suggests that the scale is able to discriminate between persons with different trait levels. Against this background, it is safe to calculate a total score for all the items or to transform the total score to Rasch measures. The advantage of the latter is that Rasch measures are linear and measured on an interval scale. Total scores are nonlinear and measured an ordinal scale (Bond \& Fox, 2007).

\section{The construct validity of the Learner Self-Directedness in the Workplace Scale}

One important outcome of the Rasch rating scale analysis was the mapping of the variable in terms of the locations of the items on the latent trait continuum. The Wright item-person map showed that the items were relatively well spread on the trait continuum. This means that the items constitute a well-defined variable.

The ordering of the items on the latent trait continuum provides information about the construct validity of the scale. The Rasch analysis revealed that items 10, 7, 8 and 14 were the most difficult items to agree with (only participants with relatively high levels of self-directedness will agree with them), whereas items 17, 16, 13 and 15 were the easiest to agree with (see Figure 1).

The 'easy' items required the participants only to indicate that they enjoy learning new things and developing new skills. These items do not explicitly require people to be active in the learning process. Even people who are relatively passive about their own work-related development may agree with these items as long as they enjoy learning new things about their jobs.

On the other hand, the 'difficult' items require people to indicate that they take active steps and even go out of their way to pursue learning opportunities. It is reasonable to conclude that only people who take responsibility for their own learning and show a real interest in their selfdevelopment will score well on these items.

The hierarchical order of the items agrees with the working definition this study used. This states that learner selfdirectedness is an internal disposition that motivates people to take responsibility for their own learning.

However, the results did show that most respondents found the 13 items relatively easy to agree with. Figure 1 shows that 
the person locations generally exceeded the item locations and that the items targeted persons at the lower end of the trait better. This means that the scale provides better quality measures for participants with relatively low standings on the learner self-directedness trait.

One should not see this as an undesirable characteristic because the usefulness of scales like the LSWS may lie mostly in their ability to identify low learner self-directedness and to measure growth in learner self-directedness (there is little point in trying to measure growth in learner selfdirectedness amongst people who already measure high on the trait). Nevertheless, the results do show that one way in which the scale can be improved is to develop some items that are more difficult to agree with. This allows for better quality measurement amongst people with high levels of learner self-directedness.

\section{Limitations of the study}

One limitation of the present study is that the researchers did not replicate the findings in an independent group of participants. It is possible that the fit of the items to the Rasch rating scale model might have capitalised on chance. The researchers addressed this issue partly by splitting the participants into calibration and replication groups and by showing that they drew similar conclusions about fit in the two groups.

Similarly, the item calibrations were invariant (within measurement error) for:

- men and women

- the calibration and replication groups

- the participants with high trait levels and those with low trait levels.

These findings support the stability of the item calibrations and the validity of the scale.

Despite these positive findings, future research should examine the replicability of the researchers' findings in this study about independent samples.

A second limitation is that the present study focused only on the internal psychometric properties of the LSWS. The findings support the construct validity of the scale. However, future studies should focus on:

- the predictive validity of the LSWS

- the discriminant and convergent validity of the scale

- the relationship of the LSWS to measures of fundamental personality traits.

It may be particularly instructive to examine whether scores on the LSWS predict positive organisational outcomes, like job involvement, organisational commitment, work adjustment and job performance.

It is also important to show the convergence of the LSWS with other measures of self-directedness and related concepts like autonomy, skills development and intrinsic motivation.

\section{Conclusion}

Although there are limitations, the study suggests that the one-dimensional Learner Self-Directedness in the Workplace Scale is a reliable measure for identifying people's levels of learner self-directedness in work environments.

Self-directed learning is beneficial for individuals as well as organisations. Having completed the instrument and after receiving an interpretation of their scores, people may develop a better understanding of their own behaviour and skills that may improve or hamper their learning attempts. When they become aware of these, they may develop strategies to become more self-directed in their learning. This may help them to adjust to changes in their work environments.

Organisations may also find the instrument useful for understanding and supporting their employees in their selfdirected learning efforts. They could also offer development programmes that incorporate an assessment of their learner self-directedness.

\section{References}

Andrich, D. (1978). A rating formulation for ordered response categories Psychometrika, 43, 561-573. doi:10.1007/BF02293814

Arthur, M.B., Khapova, S.N., \& Wilderom, C.P.M. (2005). Career success in a boundaryless career world. Journal of Organizational Behavior, 26, 177-202. doi:10.1002/job.290

Arulmani, G., \& Nag-Arulmani, S. (2004). Career counselling. A handbook. New Delhi: Tata McGraw-Hill.

Baruch, Y. (2006). Career development in organizations and beyond: Balancing traditional and contemporary viewpoints. Human Resource Management Review, 16, 125-138. doi:10.1016/j.hrmr.2006.03.002

Bartlett, J.E., \& Kotrlik, J.W. (1999). Development of a self-directed learning instrument for use in work environments. Journal of Vocational Educational Research, 24(4), 185-208.

Blackwood, C.C. (1994). Applying self-directed learning principles in the technical training of a high-risk industry. New Directions for Adult and Continuing Education, 64. San Francisco, CA: Jossey-Bass.

Bond, T.G.B., \& Fox, C.M. (2007). Applying the Rasch model: Fundamental measurement in the human sciences. Mahwah, NJ: Erlbaum.

Briscoe, J.P., \& Hall, D.T. (2006). The interplay of boundaryless and protean careers: Combinations and implications. Journal of Vocational Behavior, 4-18. doi:10.1016/j.jvb.2005.09.002

Brockett, R.G., \& Hiemstra, R. (1991). Self-direction in adult learning. Perspectives on theory, research, and practice. London: Routledge.

Chakravarthi, S., \& Vijayan, P. (2010). Analysis of the psychological impact of problem based learning (PBL) towards self directed learning among students in undergraduate medical education. International Journal of Psychological Studies, 2(1), 38-43.

Cho, I., Ellinger, A.D., \& Hezlett, S.A. (2006). An investigation of the relationship between the Bartlett-Kotrlik Inventory of Self-Learning score and demographic variables in the Korean context. Paper presented at the Academy of Human Resource Development Conference (AHRD), Columbus. Retrieved July 03, 2010, Resource Development Conference (AHRD)//eric.ed.gov/PDFS/ED492805.pdf
from http

Chuprina, L., \& Durr, R. (2006). Self-directed learners' readiness and cultural adaptability in expatriate managers. International Journal of Self-Directed Learning, 3, 13-24.

Confessore, S.J., \& Kops, W.J. (1998). Self-directed learning and the learning organization: Examining the connection between the individual and the learning environment. Human Resource Development Quarterly, 25, 365-375. doi:10.1002/hrdq.3920090407

Cseh, M., Watkins, K.E., \& Marsick, V.J. (2000). Informal and incidental learning in the workplace. In G.A. Straka (Ed.), Conceptions of self-directed learning: Theoretical and conceptual considerations (pp. 59-74). New York: Waxmann Verlag.

De Bruin, K. (2007). The relationship between personality traits and self-directed learning readiness in higher education students. South African Journal of Higher Education, 21, 228-240.

De Bruin, K., Jacobs, G.J., Schoeman, W.J., \& De Bruin, G.P. (2001). The factor structure of the Self-directed Learning Readiness Scale. South African Journal of Higher Education 15, 119-130.

Ellinger, A.D. (2004). The concept of self-directed learning and its implications for human resource development. Advances in Developing Human Resources, 6 , 158-177. doi:10.1177/1523422304263327 
Field, L. (1990). Guglielmino's Self-Directed Learning Readiness Scale: Should it be continued to be used? Adult Education Quarterly, 41, 100-103. doi:10.1177/0001848191041002004

Gorsuch, R.L. (1983). Factor analysis. Hillsdale, NJ: Erlbaum.

Guglielmino, L. (2008). Why self-directed learning? International Journal of SelfDirected Learning, 5(1), 1-14. doi:10.1002/hrdq.3920030307

Guglielmino, L. (1977). Development of the Self-Directed Learning Readiness Scale. Dissertation Abstracts International, 38, 6467.

Guglielmino, P.J., \& Murdick, R.G. (1997). Self-directed learning: The quiet revolution in corporate training and development. SAM Advanced Management Journal, $62(3), 10-18$

Guglielmino, P.J., \& Roberts, D.G. (1992). A comparison of self-directed learning readiness in US and Hong Kong samples and the implications for job performance. Human Resource Development Quarterly, 3, 261-271.

Hiemstra, R. (1994). Self-directed learning. In T. Husen \& T.N. Postlethwaite (Eds.), The International Encyclopedia of Education (p. 5394). Oxford: Pergamon Press.

Hoban, S., \& Hoban, G. (2004). Self-esteem, self-efficacy and self-directed learning Attempting to undo the confusion. International Journal of Self-Directed Learning, $1(2), 7-25$.

Klute, M.M., Crouter, A.C., Sayer, A.G., \& McHale, S.M. (2002). Occupational self-direction, values, and egalitarian relationships: A study of dual-earner couples. Journal of Marriage and Family, 64, 139-151. doi:10.1111/j.1741 3737.2002.00139.x

Knowles, M.S. (1975). Self-directed learning. New York: Association Press.

Kops, B.J., \& Pilling-Cormick, J. (2004). The changing role of trainers: Emerging trends in organizations using a self-directed approach to training. International Journal of Self-Directed Learning, 1(2), 82-94.

Linacre, J.M. (2009). Winsteps version 3.68 [Computer software]. Retrieved from http://www.winsteps.com

Linares, A.Z. (1999). Learning style of students and faculty in selected health care professions. Journal of Nursing Education, 38, 407-415.

Marsick, V.J., Watkins, K.E., Callahan, M.W., \& Volpe, M. (2009). Informal and incidental learning in the workplace. In M.C. Smith (Ed.), Handbook of research on adult learning and development, (pp. 570-600). New York: Routledge.

McDonald, R.P. (1999). Test theory. Mahwah, NJ: Erlbaum.

Merriam, S.B. (1993). An update on adult learning theory. New Directions for Adult and Continuing Education, 57. San Francisco, CA: Jossey-Bass.

Merriam, S.B., \& Caffarella, R.S. (1991). Learning in adulthood. San Francisco, CA: Jossey-Bass.
Mok, M.C., \& Lung. C.L. (2005). Developing self-directed learning in student teachers. International Journal of Self-Directed Learning, 2, 18-38.

Netemeyer, R.G., Bearden, W.O., \& Sharma, S. (2003). Scaling procedures. Issues and applications. Thousand Oaks, CA: Sage.

Oliveira, A.L., \& Simoes, A. (2006). Impact of socio-demographic and psychological variables on the self-directedness of higher education students. International Journal of Self-Directed Learning, 3(1), 1-8.

Pata, K. (2009). Modeling spaces for self-directed learning at university courses. Educational Technology \& Society, 12(3), 23-43.

Patterson, C., Crooks, D., \& Lunyk-Child, O. (2002). A new perspective on competencies for self-directed learning. Journal of Nursing Education, 41, 25-32.

Puskirich, G.M. (1993). Self-directed learning. San Francisco, CA: Jossey-Bass.

Rasch, G. (1960). Probabilistic models for intelligence and attainment tests. Chicago, IL: University of Chicago Press.

Raidal, S.L., \& Volet, S.E. (2009). Preclinical students' predispositions towards socia forms of instruction and self-directed learning: a challenge for the development of autonomous and collaborative learners. Higher Education, 57, 577-596. doi:10.1007/s10734-008-9163-z

Sabbaghian, Z.S. (1980). Adult self-directedness and self concept: An exploration of relationships (doctoral dissertation, lowa State University, 1979). Dissertation Abstracts International, 40, 3701A

Schmid, J., \& Leiman, J. (1957). The development of hierarchical factor solutions. Psychometrika, 22(1), 53-61. doi:10.1007/BF02289209

SPSS 15.0 for Windows [Computer software] (2006). Chicago, IL: SPSS Inc.

Sullivan, S.E., \& Arthur, M.B. (2006). The evolution of the boundaryless career concept: Examining physical and psychological mobility. Journal of Vocational Behavior, 69, 19-29. doi:10.1016/j.jvb.2005.09.001

Tough, A. (1971). The adult's learning projects. Toronto: Ontario Institute for Studies in Education.

Wilson, M. (2005). Constructing measures: An item response modeling approach Mahwah, NJ: Erlbaum.

Wolff, H., \& Preissing, K. (2005). Exploring item and higher order factor structure with the Schmid-Leiman solution: Syntax codes for SPSS and SAS. Behavior Research Methods, 37(1), 48-58. doi:10.3758/BF03206397, PMid:16097343

Wright, B.D., \& Masters, G.M. (1982). Rating scale analysis. Chicago, IL: MESA Press.

Zsiga, P.L. (2008). Self-directed learning in directors of a US nonprofit organization. International Journal of Self-Directed Learning, 5(2), 35-49. 